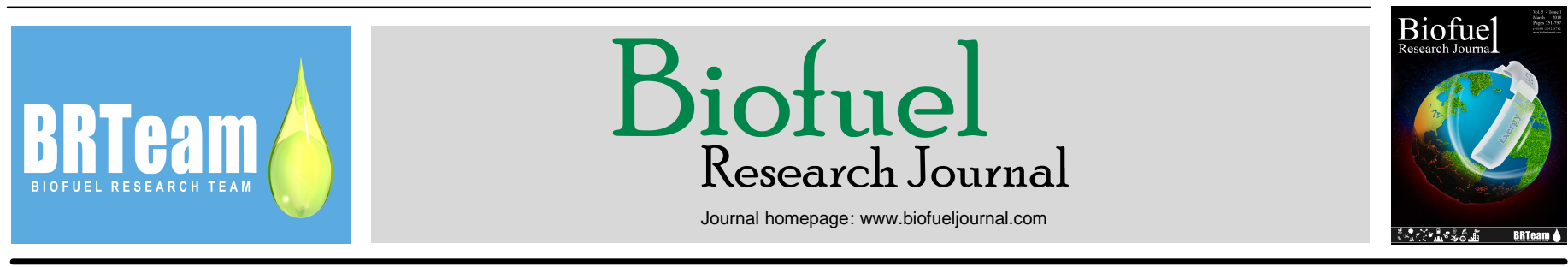

Editorial

\section{Environmental sustainability tools in the biofuel industry}

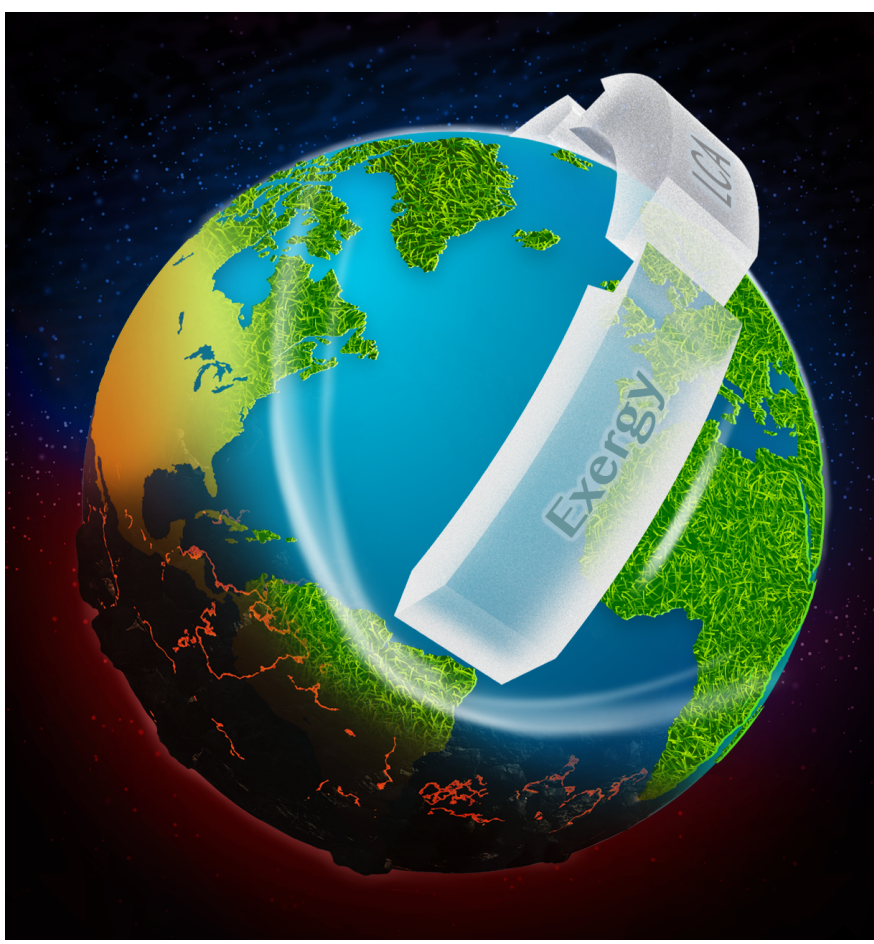

Although the biofuel industry addresses, at least partially, both energy and environmental issues, its activities utilize matter and energy and also generate wastes, potentially affecting the environment and human health. Hence, careful and serious consideration of the environmental sustainability aspects of this industry is necessary. In line with this need, increasingly advanced engineering methods and indicators are being developed and applied for decision making regarding biofuel production and utilization routes. These methods and indicators are intended to help determine the most resource-efficient, costeffective, and ecologically benign synthesis pathways and consumption patterns. Among the various methods introduced to date, those based on concepts of emergy, life cycle assessment (LCA), energy, and exergy are the most common. These methods offer great promise for the quantitative and qualitative assessment of biofuel production and consumption systems (Dadak et al., 2016), and thus should help the biofuel industry advance. These methods are briefly but critically presented herein, in order to broaden appreciation and utilization of them.

Rooted in ecology, thermodynamics, and general system theory, the emergy concept has been developed to evaluate the long-run sustainability of systems (Reza et al., 2014). In simple terms, emergy can be regarded as the solar energy expended directly or indirectly to make a product or service (Odum, 1996). Using this concept, the load imposed on the environment by a good or service can be fairly assessed. The main hypothesis behind this concept is that life in the biosphere is created and sustained by the sun. This approach can valuate/assess all energetic/material inputs as well as all non-energetic/nonmaterial terms in a consolidated unit, i.e., solar energy/exergy equivalents, by means of energy transformation ratios (transformities). Selecting the most appropriate transformity values for converting all inputs to equivalent solar energy values are the main critical steps of an emergy analysis. But, this method has conceptual and methodological drawbacks including lack of accuracy, consistency, reproducibility, and completeness. The inventory modeling principles of the LCA approach can be simulated to address the majority of these shortcomings (Raugei et al., 2014).

LCA is one of the most appropriate methodologies used to measure the complete environmental cradle to grave consequences of a product/process by quantifying energy and materials consumed as well as wastes and emissions discharged to the environment (Cornelissen and Hirs, 2002; Cherubini et al., 2009). This method can reflect well the multiple impacts on natural resource use, global climate change, and ecological well-being (Fernandez et al., 2017). In an LCA analysis, data for the relevant inputs and outputs concerning the system being analyzed are first collected, and then their related environmental impacts are specified. Finally, the results achieved in the inventory analysis and impact assessment phases are translated and interpreted (Dufour and Iribarren, 2012). Like other available environmental impact assessment methodologies, LCA suffers somewhat from arbitrariness, inaccuracies, and uncertainties. Unfortunately, these issues have always been associated with LCA studies and likely will remain so.

The majority of traditional energy analysis practices are based on the first law of thermodynamics. However, energy-based sustainability metrics cannot provide reliable insights concerning the efficiency, productivity, and sustainability of biofuel production systems, primarily due to their weaknesses in quantifying the irreversibility aspects of energy systems. Unlike energybased indicators, exergy-based measures have great potentials for resolving these issues. In addition, the exergy method is a rigorous engineering accounting technique in contrast to emergy and LCA approaches. Simply, exergy can be defined as the upper limit of a given kind of energy/material to produce useful work as it comes to complete equilibrium with a reference environment; this upper limit is achieved through reversible processes. The amount of thermodynamic irreversibilities of an engineering process is revealed by exergy analysis and is closely related to its resource depletion, revealing its degree of sustainability (Whiting et al., 2017). Furthermore, Bejan et al. (1996) state that there is a direct association between economic value and exergy, suggesting that this approach accommodates both economic and environmental aspects of energy systems as well.

In spite of its promising features, conventional exergy analysis can result in misleading conclusions if real-world economic and environmental constraints of engineering processes like biofuel production systems are not taken into consideration. Among the various approaches introduced by integrating the exergy concept with economic and environmental constraints, exergoeconomic and exergoenvironmental analyses have gained much popularity for component-level analyses of energy systems. These approaches have been 
further extended by Tsatsaronis and Morosuk (Tsatsaronis and Morosuk, 2008a and b) in order to improve the quality of the conclusions and recommendations drawn from their findings. The so-called advanced exergoeconomic and exergoenvironmental analyses decompose the irreversibility-related costs and environmental impacts into endogenous/exogenous and avoidable/unavoidable parts. The economic and environmental aspects of energy systems can also be integrated with the exergy concept using the approach called "Extended Exergy Accounting" method (Sciubba, 2001). This method can measure all externalities including capital, labor, and environmental impact in homogeneous units (Joules).

Like the other environmental impact assessment tools, the cut-off criteria need to be defined for the boundaries of an exergy analysis, affecting the accuracy of the results. In addition, the reference conditions can markedly influence the results obtained using exergy-based approaches. These issues become even more serious in exergoenvironmental analysis since this method has emerged by combining the exergy concept with the LCA approach. In addition, the Extended Exergy Accounting method is subject to double accounting issues (Rocco et al., 2014).

Overall, however, it is clear that exergy-based methods, encompassing the essences of the other sustainability assessment tools like LCA, appear to be promising tools in the analysis of biofuel production systems from thermodynamic, economic, and environmental perspectives simultaneously. The environmental sustainability tools outlined in this article are useful and should help advance the biofuel industry.

\section{References}

[1] Dadak, A., Aghbashlo, M., Tabatabaei, M., Najafpour, G., Younesi, H., 2016. Sustainability assessment of photobiological hydrogen production using anaerobic bacteria (Rhodospirillum rubrum) via exergy concept: Effect of substrate concentrations. Environ. Prog. Sustain. Energy. 35, 1166-1176.

[2] Reza, B., Sadiq, R., Hewage, K., 2014. Emergy-based life cycle assessment (Em-LCA) for sustainability appraisal of infrastructure systems: a case study on paved roads. Clean. Technol. Environ. Policy. $16,251-66$

[3] Odum, H.T., 1996. Environmental accounting: emergy and environmental decision making. Wiley.

[4] Raugei, M., Rugani, B., Benetto, E., Ingwersen, W.W., 2014. Integrating emergy into LCA: potential added value and lingering obstacles. Ecol. Modell. 271, 4-9.

[5] Cornelissen, R.L., Hirs, G.G., 2002. The value of the exergetic life cycle assessment besides the LCA. Energy Convers. Manag. 43, 1417-1424.
[6] Cherubini, F., Bird, N.D., Cowie, A., Jungmeier, G., Schlamadinger, B., Woess-Gallasch, S., 2009. Energy- and greenhouse gas-based LCA of biofuel and bioenergy systems: Key issues, ranges and recommendations. Resour. Conserv. Recycl. 53, 434-47.

[7] Fernandez, I.A.P., Liu, D-H., Zhao, J., 2017. LCA studies comparing alkaline and immobilized enzyme catalyst processes for biodiesel production under Brazilian conditions. Resour. Conserv. Recycl. 119, 117-127.

[8] Dufour, J., Iribarren, D., 2012. Life cycle assessment of biodiesel production from free fatty acid-rich wastes. Renew. Energy. 38, 155-162.

[9] Whiting, K., Carmona, L.G., Sousa, T., 2017. A review of the use of exergy to evaluate the sustainability of fossil fuels and non-fuel mineral depletion. Renew. Sustain. Energy Rev.76, 202-211.

[10] Bejan, A., Tsatsaronis, G., Moran, M.J., 1996. Thermal design and optimization. New Jersey, USA: John Wiley \& Sons.

[11] Tsatsaronis, G., Morosuk, T., 2008a. A general exergy-based method for combining a cost analysis with an environmental impact analysis. Part Itheoretical development. Proc. ASME Int. Mech. Eng. Congr. Expo. IMECE, Boston, Massachusetts, USA, pp. 67218.

[12] Tsatsaronis, G., Morosuk, T., 2008b. A general exergy-based method for combining a cost analysis with an environmental impact analysis. Part II-application to a cogeneration system. Proc. ASME Int. Mech. Eng. Congr. Expo. IMECE, Boston, Massachusetts, USA, pp. 67219.

[13] Sciubba, E., 2001. Beyond thermoeconomics? The concept of extended exergy accounting and its application to the analysis and design of thermal systems. Exergy, an Int. J. 1, 68-84.

[14] Rocco, M.V., Colombo, E., Sciubba, E., 2014. Advances in exergy analysis: a novel assessment of the Extended Exergy Accounting method. Appl. Energy. 113, 1405-1420.
Guest Editor

Marc A. Rosen

Faculty of Engineering and Applied Science University of Ontario Institute of Technology 2000 Simcoe Street North, Oshawa, Ontario, L1H $7 \mathrm{~K} 4$, Canada

Email Address: $\underline{\text { marc.rosen@uoit.ca }}$ 